\title{
Iron Reduces the Anti-Inflammatory Effect of Omega-3 Polyunsaturated Fatty Acids on the Heart of STZ- and HFD-Induced Diabetic Rats
}

\section{Maryam Khajvand-Abedini}

Hamadan University of Medical Sciences Medical School

Nasrin Ziamajidi

Hamadan University of Medical Sciences Medical School

Alireza Nourian

Bu-Ali Sina University: Bu Ali Sina University

\section{Mahdi Bahmani}

Hamadan University of Medical Sciences Medical School

Roghayeh Abbasalipourkabir ( $\nabla$ abbasalipourkabir@umsha.ac.ir)

Hamadan University of Medical Sciences Medical School https://orcid.org/0000-0002-6345-1410

\section{Original Article}

Keywords: Diabetes type 2, PUFAs, Iron, Oxidative stress

Posted Date: February 4th, 2021

DOI: https://doi.org/10.21203/rs.3.rs-176158/v1

License: (c) (1) This work is licensed under a Creative Commons Attribution 4.0 International License. Read Full License 


\section{Abstract}

BACKGROUND: This study aimed to evaluate the effects of iron and $\omega-3$ polyunsaturated fatty acids (PUFA) supplementations in the heart tissue of Wistar male rats with T2DM. After diabetes induced by HFD-STZ in animals, oxidative stress markers, including TOS, TAC, OSI (oxidative stress index), MDA, expression of RAGE, ICAM-1, VCAM-1, TNF-a, tissue level of triglyceride (TG), and total cholesterol in the heart of the rats receiving Ferrous sulfate and $\omega$-3 PUFA supplements were studied. Histopathological analysis was also performed to determine cardiac injury.

RESULTS: Significant changes in the level of oxidative stress and inflammatory factors revealed the positive effect of $\omega$-3 PUFA supplementation on diminishing the inflammatory and oxidative stress status. After comparing the group D.w.F with the group D.w, a significant decrease in the expression level of RAGE genes; inflammatory factors of TNF-a, ICAM-1, VCAM-1; the levels of MDA and OSI $(P<0.05)$; and tissue level of TNF-a protein $(P<0.01)$ was observed, indicating a negative effect of iron supplementation on $\omega-3$ PUFA anti-inflammatory properties. In addition, a substantial increment was found in the tissue levels of total cholesterol and triglycerides in groups $D$ and D.w.F compared to the group $\mathrm{CN}$, which indicates the effect of diabetes on increasing tissue accumulation of these two lipids. So, the consumption of these two supplements at the same time could intensify the effects of diabetes.

CONCLUSION: Ferrous sulfate supplementation neutralizes the anti-inflammatory properties of $\omega-3$ PUFA by increasing the oxidative stress, inflammatory markers, and tissue levels of triglycerides and total cholesterol.

\section{Introduction}

Diabetes mellitus, as one of the biggest health problems worldwide, is characterized by hyperglycemia resulted from abnormalities in insulin secretion or action (1). One of the harmful effects of hyperglycemia is causing cardiovascular complications associated with metabolic changes such as endothelial dysfunction as well as mild changes in myocardial structure (2). Long-term hyperglycemia causes a nonenzymatic reaction in glucose along with high-half-life protein molecules and lipid molecules, which is called the glycation process. Accordingly, Glycation in the pathogenesis of long-term complications of diabetes plays an important role through the recipient of the advanced glycation products (RAGEs) (3). Oxidative stress can drive glycation, while during a faulty cycle AGE (Advanced Glycation End Products), its level also increases by accelerating the oxidation process (4).

There are lots of reports on that coronary artery disease and cardiovascular complications along with endothelial dysfunction, inflammation, and heart fibrosis are common in the diabetic population (5). Cardiac inflammation is associated with an increment in the expressions of intercellular adhesive molecules (ICAM-1) and vascular adhesive molecules (VCAM-1) (6). Thus, the presence and accumulation of AGEs in diabetes through the formation of cross-linkages in collagen molecules could potentially accelerate the procedures of endothelial dysfunction, myocardial thickness and fibrosis, and 
oxidative stress, which consequently lead to damage to internal myocardial cells $(7,8)$. Therefore, increasing the level and activity of AGE increases RAGE, reactive oxygen species (ROS), expressions of ICAM-1 and VCAM-1, and inflammatory cytokines like tumor necrosis factor-a (TNF-a), which eventually result in cardiac complications in diabetes (9).

Since the long-term usage of anti-diabetic medications has several diverse side effects, during the discovery of anti-diabetic drugs, researchers have turned their attention to those dietary supplements with minimal side effects (10). Recent studies have recommended the administrations of omega-3 polyunsaturated fatty acids ( $\omega$-3 PUFAs), docosahexaenoic acid (DHA, 22:6n-3), and eicosapentaenoic acid (EPA, 20:5n-3) supplements, as effective anti-inflammatory agents on controlling and improving metabolic disorders, for patients with type 2 diabetes mellitus (T2DM) $(11,12)$.

The high sensitivity of T2DM patients to systemic inflammation, drugs, and the altered iron metabolism, which are known as risk factors for anemia in these patients, increases the risk of developing anemia in them. Additionally, due to poor diet and nutritional deficiencies of cyanocobalamin, folate, and iron, T2DM patients are more prone to nutritional anemia (13). This complication occurs simultaneously with the development of diabetes, partly due to the impaired iron absorption, which lead to renal and cardiovascular abnormalities in diabetic patients $(14,15)$. Therefore, common ferrous sulfate supplementation to manage iron deficiency anemia in diabetes causes molecular damages, which are due to the catalytic role of this supplement in the reaction of Fenton and the resulting free radicals (16).

However, the results of some in vitro studies have shown that the concomitant use of bivalent metal and $\omega-3$ PUFAs supplements can exacerbate the level of inflammation in T2DM patients, because in the presence of glucose, proteins, and divalent metals, especially for iron, w-3 PUFAs increase the productions of AGEs and malondialdehyde $(17,18)$. Several studies have shown that the productions of AGEs, oxidative stress, and other body peroxidants can be effective on increasing inflammation and dysfunction of heart tissue. Due to the lack of adequate information on the effects of $\omega-3$ PUFAs and iron supplements on the development of cardiac complications in diabetic patients or animal models of T2DM, in this study, we aimed to examine the effect of the concomitant use of iron and $\omega-3$ PUFA supplements on oxidative stress and inflammation as well as the expressions of VCAM- 1 and ICAM-1 factors in the heart tissue of the animal model T2DM.

\section{Methods}

\section{Experimental design}

Thirty Wistar male rats aged between 8 and 10 weeks and weighing between 180 and $220 \mathrm{~g}$ were prepared from the animal house of Hamadan University of Medical Sciences. The animals were then wellmaintained within the animal house under standard condition (at $22-24^{\circ} \mathrm{C}$ with $12: 12$ hours light and dark cycle) with free access to food and water. Subsequently, the animals were randomly divided into five groups ( $n=6$ in each group) as follows: 
1. (CN): Control normal group with no treatment.

2. (D): Diabetic control group with no treatment.

3. (D. $\omega)$ : The diabetic group received $\omega-3$ PUFAs supplement.

4. (D.F): The diabetic group received $\mathrm{Fe}^{2+}$ supplement.

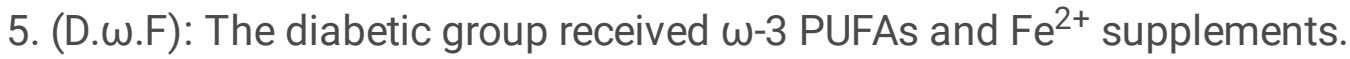

Groups 2 to 5 received high-fat diet with $60 \%$ fat (HFD) for 8 weeks and a single-dose of $40 \mathrm{mg} / \mathrm{kg}$ streptozotocin (STZ) in citrate buffer with $\mathrm{pH}=4.5$ intraperitoneally after five to six hours fasting (19). Group 1 has also received a normal diet for 8 weeks. Fasting blood sugar (FBS) obtained from tail blood sampling was then measured at 12 and 72 hours after the STZ administration using a strip-operated blood sugar sensor (Accuchek; Roche, Germany). Animals with FBS $>250 \mathrm{mg} / \mathrm{dL}$ were considered as T2DM model. The treatment regimen used in this study was based on a 40-day period. Accordingly, this regimen included daily gavage of moderate doses of iron sulfate $(35 \mathrm{mg} / \mathrm{kg} / \mathrm{day}(16,20)$ and $\omega-3$ PUFAs supplements ( $45 \mathrm{mg} / \mathrm{kg}$ EPA and $30 \mathrm{mg} / \mathrm{kg} \mathrm{DHA}$ ) (21), in the designed groups and groups 1 and 2 have received normal saline solution. Thereafter, the rats were sacrificed and their hearts were dissected, washed rapidly with cold phosphate-buffered saline (PBS, pH 7.4), frozen in liquid nitrogen, and finally kept at $-70^{\circ} \mathrm{C}(16,21)$. The composition of high-fat diet is presented in Table $1(22)$.

Table 1

Composition of HFD $(\mathrm{g} / \mathrm{kg})$.

\begin{tabular}{|lll|}
\hline Class description & Ingredients & Grams \\
\hline Protein & Casein, Lactic, 30 Mesh & $200.00 \mathrm{~g}$ \\
\hline Carbohydrate & Cystine, L & $3.00 \mathrm{~g}$ \\
& Lodex 10 & $125.00 \mathrm{~g}$ \\
\hline Fiber & Sucrose, Fine Granulated & $72.80 \mathrm{~g}$ \\
\hline Fat & Solka Floc, FCC200 & $50.00 \mathrm{~g}$ \\
\hline Mineral & Lard & $245.00 \mathrm{~g}$ \\
\hline Vitamin & Soybean Oil, USP & $25.00 \mathrm{~g}$ \\
\hline Dye & S10026B & $50.00 \mathrm{~g}$ \\
\hline Solka Floc: powdered cellulose, Lard: semi-solid white fat of pig, Fine Granulated: a type of sugar, \\
\hline S10026B: mineral mix formula, V10001C: vitamin mix fotmula. & $2.00 \mathrm{~g}$ \\
\hline
\end{tabular}




\section{Preparation of cardiac homogenates}

About $100 \mathrm{mg}$ of heart tissue was weighed, washed three times with ice-cold PBS, and then homogenized with liquid nitrogen. The obtained mixture was re-suspended in ice-cold lysis buffer (10 mM (4-(2hydroxyethyl)-1-piperazineethanesulfonic acid), $10 \mathrm{mM} \mathrm{KCl}, 1.5 \mathrm{mM} \mathrm{MgCl} 2,1 \mathrm{mM}$ EDTA, 0.1\% Triton $\mathrm{X} 100$, and protease inhibitor cocktail, $\mathrm{pH}=7.9$ ) and then incubated on ice for $20 \mathrm{~min}$. Thereafter, homogenate was centrifuged at $10000 \mathrm{~g}$ for $15 \mathrm{~min}$ at $4{ }^{\circ} \mathrm{C}$ to remove tissue remnants. The supernatant was finally restored at $-70^{\circ} \mathrm{C}$ until measuring the TAC \& TOS parameters (23).

\section{TOS assay}

The determination of the TOS level was conducted in the obtained tissue samples using the ferrous ion oxidation xylenol orange (FOX1) method. Notably, the basis of this method is the oxidation of ferrous ions to ferric ions in the presence of oxidizing agents and under acidic conditions. Finally, the ferric ions formed by the xylene orange produced a color complex, which was detected at a wavelength of $560 \mathrm{~nm}$ (24).

\section{TAC assay}

The TAC level was determined in the obtained tissue samples using the ferric reducing antioxidant potential (FRAP) method. Notably, the basis of this method is the reduction of ferric tripyridyl triazine (FellITPTZ) to ferropyridyl triazine (FellTPTZ) in the presence of biological antioxidant agents. Finally, ferrous pyridyl triazine (FellTPTZ) formed a blue complex whose absorption was compared to that of a known standard $\left(\mathrm{FeSO}_{4} \cdot 7 \mathrm{H}_{2} \mathrm{O}\right)$ at $593 \mathrm{~nm}(25)$.

\section{Lipid peroxidation assay}

The determination of aldehydes produced during lipid peroxidation was conducted in the obtained homogenate in terms of the manufacturer's instructions by TBA (thiobarbituric acid) reaction (26). Notably, the basis of this method is the reaction of MDA, which is the end product of lipid peroxidation, along with TBA to produce a color complex. Finally, the TBA assay kit (Kiazist, Iran) was used in terms of the manufacturer's instructions, and the MDA value was then reported as nanomoles per mg protein.

\section{Total protein assay}

Protein content was determined in the homogenized tissue used for each assay using the Bradford method. Correspondingly, in this method, $750 \mu \mathrm{L}$ of Kumasi Blue was mixed with $50 \mu \mathrm{L}$ of the samples and then incubated for 10 minutes at room temperature. At last, the absorbance of the samples was measured at $595 \mathrm{~nm}$. A standard curve for bovine serum albumin (BSA) was also drawn up (27).

\section{ELISA analysis of TNF- $a$}


After preparing of heart homogenate, TNF-a protein concentration was determined in terms of the manufacturer's instructions using Rat TNF-a ELISA MAX ${ }^{\mathrm{TM}}$ Deluxe set kit (BioLegend, San Diego, USA).

\section{Measurement of heart total cholesterol and triglyceride content}

The heart tissue lipid of the animals was measured by the method described by Folch et al. (1957) (28). After the homogenization of the tissue $(\approx 50 \mathrm{mg})$ in liquid nitrogen and radio-immunoprecipitation assay (RIPA) buffer, the tissue sample was re-suspended in chloroform-methanol solution (1:2) with a final volume of 20 folds of the weight. Afterward, the homogenate was centrifuged to recover the liquid phase, and the solvent was then washed with $0.9 \% \mathrm{NaCl}$ ( $4 \mathrm{~mL}$ for a mixture of $20 \mathrm{~mL}$ volume). To separate the 2 phases, the mixture was centrifuged at $1000 \mathrm{~g}$ (10 min), the upper phase was removed, and the lower chloroform phase containing tissue lipids was evaporated in a vacuum containing $\mathrm{N}_{2}$ gas. Triglyceride and cholesterol assay kits (Pars Azmun, Iran) were used to measure total cholesterol and triglyceride contents of heart tissue.

\section{RAGE, TNF-a, ICAM-1, and VCAM-1 genes' expressions}

Cardiac tissue RNA extraction was conducted using Kiazol reagent in terms of the manufacturer's protocol (Kiazist, Iran). Thereafter, the nano drops and 1\% agarose gel electrophoresis were applied to ensure its quality. Some of the total RNA extracted $(1-5 \mu \mathrm{g})$ were reversely transcribed into cDNA using a cDNA synthesis kit (CinaClon, Iran). Next, a combination of $2 \mu \mathrm{L}$ of cDNA made with $10 \mu \mathrm{L}$ of SYBR Green, $1 \mu \mathrm{L}$ of the leading primer, and $1 \mu \mathrm{L}$ ladder primer, was used for RT-PCR (The sequence of primers is presented in Table 2). Subsequently, real time-PCR (RT-PCR) was done using the Light Cycler ${ }^{\circledR} 96$ system (Roche, USA). The Amplification Protocol with 40-45 cycles is shown in Table 3.

Table 2

The sequences of the primers utilized in the RT-PCR in this research.

\begin{tabular}{|c|c|c|c|}
\hline Gene & Forward primer & Reverse primer & $\begin{array}{l}\text { Product } \\
\text { size }\end{array}$ \\
\hline ACTB & 5】-CCCGCGAGTACAACCTTCT-3》 & 5囚-CGTCATCCATGGCGAACT-3】 & 72 (bp) \\
\hline RAGE (Rat) & $\begin{array}{l}\text { 5'- } \\
\text { GAGTCCGAGTCTACCAGATTCC- } \\
3^{\prime}\end{array}$ & $\begin{array}{l}\text { 5'- } \\
\text { GGTCTCCTCCTTCACAACTGTC-3 }\end{array}$ & $191(\mathrm{bp})$ \\
\hline TNF-a (Rat) & $\begin{array}{l}\text { 5囚-TGTTCATCCGTTCTCTACCCA- } \\
3 \rrbracket\end{array}$ & 5囚-САCTACTTCAGCGTCTCGT-3囚 & 196 (bp) \\
\hline $\begin{array}{l}\text { ICAM-1 } \\
\text { (Rat) }\end{array}$ & 5囚-GACATTGGGGAAGACAGCA-3】 & 5囚-TCCACTCGCTCTGGGAAC-3】 & $104(\mathrm{bp})$ \\
\hline $\begin{array}{l}\text { VCAM-1 } \\
\text { (Rat) }\end{array}$ & $\begin{array}{l}\text { 5囚-CTGGGAAACTGGAAAGAGGA- } \\
3 \rrbracket\end{array}$ & $\begin{array}{l}\text { 5囚-GCCAAACACTTGACCATGAC- } \\
3 \rrbracket\end{array}$ & $115(\mathrm{bp})$ \\
\hline
\end{tabular}


Table 3

The amplification protocol with $40-45$ cycles

\begin{tabular}{|llllll|}
\hline Gene & Preincubation & Denaturation & Annealing & Extention & Data acquisition \\
\hline ACTB & $95^{\circ} \mathrm{C}, 900 \mathrm{~s}$ & $95^{\circ} \mathrm{C}, 20 \mathrm{~s}$ & $58^{\circ} \mathrm{C}, 30 \mathrm{~s}$ & $72^{\circ} \mathrm{C}, 30 \mathrm{~s}$ & $0.5^{\circ} \mathrm{C}, 0.5 \mathrm{~s}$ \\
\hline RAGE & $95^{\circ} \mathrm{C}, 900 \mathrm{~s}$ & $95^{\circ} \mathrm{C}, 20 \mathrm{~s}$ & $56^{\circ} \mathrm{C}, 30 \mathrm{~s}$ & $72^{\circ} \mathrm{C}, 30 \mathrm{~s}$ & $0.5^{\circ} \mathrm{C}, 0.5 \mathrm{~s}$ \\
\hline TNF-a & $95^{\circ} \mathrm{C}, 900 \mathrm{~s}$ & $95^{\circ} \mathrm{C}, 20 \mathrm{~s}$ & $56^{\circ} \mathrm{C}, 30 \mathrm{~s}$ & $72^{\circ} \mathrm{C}, 30 \mathrm{~s}$ & $0.5^{\circ} \mathrm{C}, 0.5 \mathrm{~s}$ \\
\hline ICAM-1 & $95^{\circ} \mathrm{C}, 900 \mathrm{~s}$ & $95^{\circ} \mathrm{C}, 20 \mathrm{~s}$ & $59^{\circ} \mathrm{C}, 30 \mathrm{~s}$ & $72^{\circ} \mathrm{C}, 30 \mathrm{~s}$ & $0.5^{\circ} \mathrm{C}, 0.5 \mathrm{~s}$ \\
\hline VCAM-1 & $95^{\circ} \mathrm{C}, 900 \mathrm{~s}$ & $95^{\circ} \mathrm{C}, 20 \mathrm{~s}$ & $59^{\circ} \mathrm{C}, 30 \mathrm{~s}$ & $72^{\circ} \mathrm{C}, 30 \mathrm{~s}$ & $0.5^{\circ} \mathrm{C}, 0.5 \mathrm{~s}$ \\
\hline $\begin{array}{l}\text { Actin Beta: } \beta \text {-actin, Receptor for advanced glycation end products: RAGE, tumor necrosis factor-a: } \\
\text { TNF-a, Intercellular Adhesion Molecule-1: ICAM-1, Vascular Cell Adhesion Molecule-1: VCAM- }-1 .\end{array}$ \\
\hline
\end{tabular}

At the end of each cycle, the fluorescence signal was recognized. During this process, the $\beta$-actin gene was utilized as an internal control. The relative expression of the gene was achieved by counting the number of PCR cycles (CT) using a comparative method $\mathrm{CT}\left(\triangle \mathrm{CT}, \triangle \mathrm{CT}=\mathrm{CT}_{\beta \text {-actin }}-\mathrm{CT}_{\text {target gene }}\right)$. Method $2^{-\triangle \triangle C T}$ was also used to evaluate the relative expression of each gene in the control and treatment groups.

\section{Histological evaluation}

The formalin-fixed heart tissue samples were dehydrated in ascending ethanol concentrations, cleared in xylene, infiltrated, and then embedded in paraffin. They were then sectioned at $5 \mu \mathrm{m}$ thick using a rotary microtome (Leica RM2255, Germany). Afterward, these sections were stained with hematoxylin and eosin (H\&E), and studied independently by a pathologist using a light microscope (Olympus CX41, Japan) equipped with a digital camera (Olympus DP25, Germany).

\section{Statistical analysis of the data}

The experimental results are expressed as the means \pm SEM. All the statistics were performed using the SPSS software version 16.0 (SPSS for Windows; http://www.spss.com) and GraphPad Prism version 8.0 (http://www.graphpad.com). To find out the difference, a one-way analysis of variance (ANOVA) was used, followed by the Tukey test. The level of $p<0.05$ was considered as statistically significant.

\section{Results}

\section{Fasting blood sugar and body weight}

Before and after the treatment, body weight (BW) and FBS change of all rats were recorded. As shown in Tables 4 and 5, BW gain was not significantly different among the groups. Before the treatment, FBS has 
significantly increased in diabetic rats $(p<0.001)$ compared to the normal control group. After the treatment, both FBS and BW also revealed a significant $(p<0.001)$ increase in diabetics groups compared

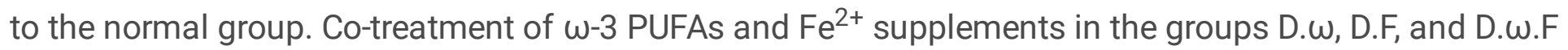
led to a significant $(p<0.01$ and $p<0.001$, respectively) reduction in $\mathrm{BW}$ compared to the normal control rats.

Table 4

Effect of treatment on the body weight changes $(\mathrm{g})$ of the experimental groups

\begin{tabular}{|c|c|c|c|c|}
\hline Groups & $\begin{array}{l}\text { Before starting } \\
\text { HFD }\end{array}$ & $\begin{array}{l}\text { Eight weeks after } \\
\text { HFD }\end{array}$ & $\begin{array}{l}\text { Before starting } \\
\text { treatment }\end{array}$ & $\begin{array}{l}\text { After } 40 \text { days of } \\
\text { treatment }\end{array}$ \\
\hline $\mathrm{CN}$ & $216.40 \pm 1.72$ & $305.80 \pm 7.87$ & $337.20 \pm 6.51$ & $430 \pm 16.02$ \\
\hline D & $216 \pm 2.28$ & $340.80 \pm 2.69$ a \# & $356.40 \pm 13.73$ & $332.20 \pm 11.88^{a * *}$ \\
\hline D.w & $224.60 \pm 4.38$ & $347.20 \pm 4.05$ a \# & $350.60 \pm 14.05$ & $329.40 \pm 10.04^{a * *}$ \\
\hline D.F & $218.20 \pm 3.26$ & $354 \pm 4.06^{a ~ \#}$ & $352.60 \pm 12.85$ & $326 \pm 18.04^{a * *}$ \\
\hline D.w.F & $221.60 \pm 4.98$ & $352.80 \pm 1.46^{a ~ \#}$ & $338.20 \pm 8.63$ & $316 \pm 15.65^{a ~ \#}$ \\
\hline \multicolumn{5}{|c|}{$\begin{array}{l}\text { Control normal group: CN, Diabetic control group: D, the diabetic group received } \omega-3 \text { PUFAs } \\
\text { supplement: D. } \omega \text {, The diabetic group received } \mathrm{Fe}^{2+} \text { supplement: D.F, The diabetic group received } \omega-3 \\
\text { PUFAs and Fe }{ }^{2+} \text { supplements: D. } \omega . \mathrm{F} \text {. Data are shown as mean } \pm \text { SEM. (** } p<0.01, \# p<0.001, \text { ns } p> \\
0.05) .{ }^{\text {a }} \text { Significantly different from control. }\end{array}$} \\
\hline
\end{tabular}

Table 5

Effect of treatment on the FBS changes $(\mathrm{mg} / \mathrm{dL})$ of the experimental groups

\begin{tabular}{|c|c|c|c|c|}
\hline Groups & $\begin{array}{l}\text { Before starting } \\
\text { HFD }\end{array}$ & $\begin{array}{l}\text { Eight weeks after } \\
\text { HFD }\end{array}$ & $\begin{array}{l}\text { Before starting } \\
\text { treatment }\end{array}$ & $\begin{array}{l}\text { After } 40 \text { days of } \\
\text { treatment }\end{array}$ \\
\hline $\mathrm{CN}$ & $74.10 \pm 9.267$ & $74.30 \pm 7.514$ & $73 \pm 5$ & $86.40 \pm 4.44$ \\
\hline D & $78.50 \pm 8.797$ & $84.40 \pm 8.702$ & $305.40 \pm 26.35^{\text {a \# }}$ & $309 \pm 28.11$ a \# \\
\hline D.w & $79.60 \pm 10.25$ & $84.20 \pm 14.77$ & $328.20 \pm 21.57^{a ~ \#}$ & $317.20 \pm 29.12^{a ~ \#}$ \\
\hline D.F & $77.50 \pm 13.13$ & $78.60 \pm 10.16$ & $345.40 \pm 22.21^{a ~ \# ~}$ & $365.60 \pm 16.32^{a ~ \#}$ \\
\hline D.w.F & $81.60 \pm 10.09$ & $79.60 \pm 10.24$ & $376.60 \pm 10.38^{a ~ \#}$ & $378 \pm 12.39$ a \# \\
\hline \multicolumn{5}{|c|}{$\begin{array}{l}\text { Control normal group: CN, Diabetic control group: D, the diabetic group received } \omega-3 \text { PUFAs } \\
\text { supplement: D. } \omega \text {, The diabetic group received Fe }{ }^{2+} \text { supplement: D.F, The diabetic group received } \omega-3 \\
\text { PUFAs and Fe }{ }^{2+} \text { supplements: D. } \omega . \text { F. Data are shown as mean } \pm \text { SEM. }(\# p<0.001) .{ }^{a} \text { Significantly } \\
\text { different from control. }\end{array}$} \\
\hline
\end{tabular}




\section{Evaluation of oxidative stress markers in cardiac homogenates}

The results of TAC and TOS, as oxidative stress markers, and OSI (oxidative stress index) and MDA (final product of lipid peroxidation) are shown in Fig. 1 (A-D). As shown in Fig. 1-A, there is a significant decrease in the level of TAC tissue in the groups $\mathrm{D}$ and $\mathrm{DF}(p<0.001)$ and the group D.w.F $(p<0.05)$ compared to the group CN. Additionally, groups $D$ and D.F exhibited a significant decrease in TAC compared to the group D. $\omega$ ( $p<0.001$ and $p<0.05$, respectively).

Figure 1-B displays a notable increase in the level of tissue of TOS in the groups $D$ and D.w.F compared to the groups $\mathrm{CN}(p<0.01)$ and D. $\omega(p<0.01)$. After comparing the group D.F with the group $\mathrm{CN}$, an increase in TOS level was observed $(p>0.05 ; p=0.064)$; however, it was not significant.

According to Fig. 1-C, the groups D $(p<0.001)$, D.F, and D.w.F $(p<0.01)$ had a significant increase in OSI compared with the group CN. Moreover, the groups $\mathrm{D}(p<0.001)$, D.F, and D.w.F $(p<0.05)$ showed a remarkable increase in OSI compared to the D. $\omega$, group. As shown by the results of MDA levels, as an indicator of cardiac lipid peroxidation, in Fig. 1-D, the groups D, D.w.F $(p<0.01)$, and D.F $(p<0.05)$ showed a significant increase in MDA level compared to the group $C N$. In addition, the group D.w.F has also reduced MDA levels, which was not significant $(p>0.05 ; p=0.06)$.

\section{TNF-a protein level in the cardiac tissue}

ELISA method was used to evaluate the tissue level of TNF-a protein. According to Fig. 2, the groups D and D.w.F had a significantly increase in tissue level of TNF-a protein in comparison with the groups $\mathrm{CN}$ $(p<0.01)$ D. $\omega(p<0.05$ and $p<0.01$, respectively). Additionally, the group D.F showed a significant increase in tissue level of TNF-a protein compared to the group $\mathrm{CN}(p<0.05)$.

\section{TG and total cholesterol levels in cardiac tissue}

Figure 3 (A-B) shows the tissue levels of triglyceride and total cholesterol in the hearts of the studied rats. The TG and total cholesterol levels had a significant increase in the group D compared to the group CN ( $p$ $<0.05)$. Furthermore, tissue levels of TG and total cholesterol have significantly increased in the group D.F compared to the group $\mathrm{CN}(p<0.01$ and $p<0.001$, respectively). On the other hand, the level of these lipids showed a significant increase in the group D.F compared to the group D. $\omega(p<0.01)$. After comparing the group D. $\omega$ with the group $D$, a significant decrease was observed in TG and Total-Cho levels ( $p>0.05 ; p=0.084$, and $p=0.077$, respectively). A comparison of the D.w.F group with the D.F group also showed a significant decrease in the levels of two lipids $(p<0.05)$.

\section{Gene expression of cardiac inflammation markers}

The mRNA levels of RAGE, TNF- $a$, ICAM-1, and VCAM-1 genes were determined in the hearts of all the studied groups' rats using QRT-PCR analysis. The groups D, D.F, and D.w.F showed significantly increased gene expressions of RAGE $(p<0.001)$ and ICAM-1 $(p<0.05)$ in comparison with the group CN (Figs. <link rid="fig4" $>4</$ link $>-A$ and 4-B). However, the groups D and DF had a significant increase in the expression 
of the TNF-a gene compared to the group $\mathrm{CN}(P<0.001$, Fig. $4-\mathrm{C})$. Besides, the expression of VCAM-1 gene has significantly increased in the groups $D$ and D.F compared with the $C N$ group $(p<0.001$ Fig. 4 -D). Comparison of the group D.w.F with the $\mathrm{CN}$ group also showed an increase in mRNA expressions of TNF$a$ and VCAM-1 genes ( $p<0.0014-C$ and $p<0.014$-D, respectively). In the expressions of RAGE, ICAM- 1 , TNF-a, and VCAm-1 genes, the group D had a significant increase compared to the group D. $\omega(p<0.05)$. In addition, the comparison of the D.w.F group with the D.w group showed a significant increase in TNF-a gene expression level ( $p<0.01$ Fig. $4-C)$ as well as a an increase in VCAM-1 gene expression level; however, it was not significant ( $p>0.05 ; p=0.096$ Fig. 4-D). RAGE gene expression increase in the D.F group was not significant compared to the group D. $\omega(p>0.05 ; p=0.075$ Fig. 4 -A). Following the comparison of the group D.F with the group D. $\omega$, a significant increase was observed in the expression levels of ICAM-1 and VCAM-1 genes $(P<0.05$, Figs. <link rid="fig4" $>4</$ link $>-B$ and $4-D)$.

\section{Structural changes in cardiac tissue}

The photomicrograph of a longitudinal section of the cardiac tissues of rats is shown in Fig. 5. A: group $\mathrm{CN}$ with the characteristic histology of the heart showing a normal myocardial morphology with cross striation $(\uparrow)$ and typical nuclei $(\uparrow)$ in the middle of the cardiomyocytes, which are longitudinally interconnected by intercalated discs (ID) ( $\mathbf{\Delta}$ ). B: group DM exhibiting the fragmented cardiomyofibers ( $\uparrow$ ) with degenerating, square-shaped swelling nuclei $(\uparrow)$ as well as hypercontracted segments $(*)$ along with the widened IDs $(\boldsymbol{\Lambda})$, indicating the initial stage of coagulative necrosis. C: D.F group showing degenerative changes including cellular fragmentation $(\uparrow)$, nuclear swelling and fading $(\uparrow)$, and widening of the IDs $(\boldsymbol{\Lambda})$. D: D.w.F group demonstrating the fragmentation of cardiomyocytes containing hypercontracted segments $(*)$ with the ruptured myofibrils $(\uparrow)$ and degenerating nuclei $(\uparrow)$ as well as widening the gap of IDs $(\mathbf{\Lambda})$. E: D.w group showing the regeneration of the myocardial tissue toward the normal histology with rare, if any is detected, degenerative changes such as square-shaped nuclei $(\uparrow)$ and gapping the IDs ( $\mathbf{\Delta})$.

\section{Discussion}

According to the results of the present research, there is a notable increase in BW following HFD utilization. Moreover, it was found that some strains (Wistar and Sprague-Dawley rats) are more vulnerable to obesity when receiving HFD, which may be due to the hyperphagic nature of these animals that are resistant to the insulin function and the reduced hypothalamic peptides. Furthermore, the alterations in BW gain mostly depend on a large extent fat composition of the diet (29-31), the deposition of the saturated fats resulted from the consumption of a diet rich in energy in different layers of body fat due to the reduced energy consumption compared to animals fed with a normal diet $(32,33)$. A non-significant BW loss was also shown in our results after the injection of STZ that can increase levels of leptin and adiponectin and a concurrency between adipogenesis and lipolysis in the diabetic rats (34, 35). The reduced BW in diabetic rats in the present study is consistent with the results of the Gundala's study in 2019 (36). It was suggested that $\omega$-3 PUFA enhances lipid oxidation through the activation of peroxisome proliferator-activated receptor a (PPAR a) and suppression of lipogenic enzymes, which make 
obesity resistance $(37,38)$. Additionally, Li et al. (2012) (39) in their study reported that iron can cause loss of BW in HFD/STZ-treated rats compared to the control group. However, its precise mechanism has not been determined yet (39).

Sahin et al. 2007 (40) suggested that the HFD/STZ model can be considered as a novel animal model for the induction of T2DM and the study of antidiabetic and anti-inflammatory compounds (40). Srinivasan et al. (2005) reported a significant increase in FBS in diabetic rats after the STZ injection compared to the normal control group (34). This is likely due to compensatory hyperinsulinemia to control glucose homeostasis (41). After the treatment period, FBS levels were significantly higher in diabetic groups compared to the normal control group. Besides, a non-significant decrease in FBS levels were observed in the D. $\omega$ group. The positive effect of $\omega-3$ PUFA on increasing glycolysis and glycogenesis and its negative effect on lowering FBS levels via increasing insulin resistance and exacerbating glucose intolerance have also been reported (42) (43-46).

The mechanisms of STZ include elective devastation of pancreatic beta cells and a decreased activity of insulin secretion $(47,48)$. It was shown that chronic hyperglycemia leads to the formation of AGE through the glycation process of long half-life proteins and lipids. Accordingly, the accumulation of these compounds and their binding to RAGE cause cross-linking in collagen molecules, which consequently increase myocardial thickness, oxidative stress, and fibrosis, and eventually damage myocardial cells ( 7 , 8). Furthermore, it has been reported that oxidative stress can lead to the development of the glycation process. In contrast, it was found that AGE increases its level by accelerating the oxidation process (4). Thus, the oxidative stress caused by the binding of AGE to its receptor, in turn, leads to numerous pathological changes in the gene expression and impairs the structure and function of the heart in diabetic patients $(49,50)$. According to the findings of the present study, the increased OSI was observed in the heart tissues of the groups D, D.F, and D.w.F compared to the $\mathrm{CN}$ group. Moreover, there was a significant increase in the OSI level in the groups D, D.F, and D.w.F compared to the D.w group. Furthermore, the administration of $\omega-3$ PUFA as a supplement, significantly reduced OSI compared to the group D.

In line with the findings pf a study by Flavia et al (2014), the effective role of iron supplements in the high production of ROS was one of the major mechanisms proposed to explain cardiac changes, myocardial cell death, and cardiac fibrosis in diabetic rats (51). Ginty and Conklin (2012) suggested that the $\omega-3$ PUFA diet may improve the antioxidant capacity of diabetic rats (52). In the present study, it was expected that iron supplementation would have a negative outcome on the antioxidant effect of $\omega$-3 PUFA supplementation. After comparing the group D.W.F with the group D.F, it was found that the level of OSI has more significantly increased. Therefore, concurrent use of both supplements in diabetics can reduce the oxidative capacity, may be due to the negative effect of free radicals, resulted from the reactions of the divalent metal iron, on the antioxidant properties of $\omega$-3 PUFA. In contrast, some studies have shown that diets containing fish oil, besides increasing cellular oxidative damage, produce antioxidant effects (30). 
Based on the evidence, ferrous sulfate causes damage to cell membranes and their lipoproteins. This damage occurs through high production of toxic hydroxyl radicals resulted from the Fenton/Haber-Weiss reaction, followed by the free radical chain reaction, called lipid peroxidation, and the increased production of malondialdehyde (53). It is noteworthy that some factors like AGEs cause a substantial rise in PUFA peroxidation and MDA production in the presence of $\mathrm{Fe}^{+2}$ and $\mathrm{Fe}^{+3}$ (54). In the present study, it was found that the groups D, D.F, and D.w.F had a significant increase in MDA level, as a lipid peroxidation index, in comparison with the group $\mathrm{CN}$, probably due to the effect of divalent metals on raising the amount of lipid peroxidation. However, there was a non-significant decrease in lipid peroxidation in the group D.w compared to the group D. Additionally, a study by Wei Bao et al. (2012) showed that there is no association between dietary or supplementation of iron and the risk of T2DM (55).

According to the results, gene expression of RAGE significantly increased in the heart tissues of the group $\mathrm{D}$ compared to the group $\mathrm{CN}$. In addition, compared to $\mathrm{CN}$ group, the induction of T2DM in group $\mathrm{D}$ more increased gene expression and tissue level of TNF-a, as an inflammatory cytokine, as well as gene expressions of ICAM- 1 and VCAM-1, as cardiac inflammation markers. These results are consistent with the findings of the studies by Evangelista et al. $(2019)$ and Cheng et al. $(2017)(9,56)$.

According to the previous reports, it can be concluded that by increasing tissue level of AGE, tissue level of ROS; the gene expressions of RAGE, ICAM-1, VCAM-1; and inflammatory cytokines such as TNF-a increase. However, the increased levels of these factors eventually lead to some cardiac complications and diabetic cardiomyopathy $(9,57)$.

Tschöpe et al. in 2005 suggested a possible mechanism regarding the correlation among the genes expression of CAMs, cardiac inflammation, and cardiomyopathy in diabetic situation. According to their report, several pathogenic mechanisms such as the expression of pro-inflammatory cytokines, oxidative stress, and hyperglycemia, are responsible for the induction of endothelial CAMs. So, there is a significant relationship between cardiac parameters and the inflammatory endothelial activation through the elevated levels of CAMs (ICAM-1 and VCAM-1) and proinflammatory cytokines (TNF- $a$ and IL-1 $\beta$ ) induced by CAMs (6). Under the hyperglycemic conditions, the role of transitional metals such as copper and iron in protein glycation process and ultimately in the pathogenesis of cardiac diabetic complications have been identified. The high affinity of the glycosylated proteins to transitional metals leads to the maintenance of the reduced and active state of the metal and ultimately catalytic oxidation (58). Nevertheless, prescribing iron and vitamin supplements as well as the supplements containing DHA and EPA, as anti-inflammatory agents, to T2DM patients are recommended to control and improve metabolic disorders effectively $(11,12)$. Omega-3 lowers obstruction, inflammation, fibrosis, and hypertrophy caused by heart disease through disrupting JNK signaling, reducing TNF-a expression, and producing molecules involved in cardiac inflammation such as ICAM-1 and VCAM-1 (59-61). Besides, the expression of genes and tissue level of the TNF-a have significantly induced in the D.w.F group compared to the D.w group. In the current study, it was found that only the D.w group significantly decreased gene expressions of RAGE and TNF- $a$ and tissue level of TNF-a protein. It was also found that the gene 
expressions of RAGE and TNF-a, and tissue level of TNF-a protein significantly increased in the groups D.F, D.w.F, CN, and D.F compared to the group D.w. Although the administration of omega-3 alone decreased genes expression of ICAM-1 and VCAM-1 compared to the group D, co-treatment with Fe and omega-3 in diabetic rats led to a significant increase and a non-significant increase in the levels of genes ICAM-1 and VCAM-1, respectively. It was also found that in hyperglycemia, iron supplementation has a negative effect on the anti-inflammatory properties of $\omega$-3 PUFAs by catalyzing their oxidation (62). In contrast, a study by Kosacka (2016) reported that a lack of iron in the diet caused a mild inflammation in diabetic rats (63).

A diabetic animal model with STZ-HFD induced mild hyperglycemia, hypertriglyceridemia, hypercholesterolemia, and conditions similar to insulin resistance in pre-diabetic humans. In this regard, it seems that the induction of diabetes mainly occurs through the glucose-fatty acid cycle or Randle cycle (64). Following diabetes disease and its significant effect on changing plasma and tissue lipid profiles, the increased tissue deposition of cholesterol and triglycerides and the increased risk of cardiomyopathy occur in patients with T2DM. Naidu et al. in their study in 2015 reported that the increased levels of blood triglyceride and cholesterol followed by a significant increase in their tissue levels have occurred in the hearts of HFD-STZ-induced diabetic rats compared with the normal group. By inducing T2DM in an animal model, following the consumption of HFD, uptake, and formation of triglycerides in the form of chylomicrons, the production of endogenous very-low-density lipoprotein rich of TG (VLDL-1, VLDL-2) has increased, and triglyceride uptake by peripheral tissues through a low lipoprotein lipase (LPL) activity has decreased. Therefore, it can be stated that hypertriglyceridemia and its cardiovascular complications are caused by diabetes (10). The findings of the present study showed that the levels of cholesterol and triglycerides were significantly higher in the heart muscle tissues of the group D compared to the group $\mathrm{CN}$. On the other hand, several studies have shown the relationship of the level of triglyceride accumulation in heart tissue with heart dysfunction in patients with $\operatorname{T2DM}(65,66)$. However, this relationship has been rejected in a study by by McGavock et al. in 2012 (67). A prominent feature in several models of cardiomyopathy is the intracardiac accumulation of TG due to the impaired cardiac free fatty acids (FFAs) metabolism and FFAs leakage into the heart. Additionally, adipose tissue, as the source of most of the circulatory FFAs due to lipolysis, can indirectly affect cardiac metabolism by affecting the serum concentrations of the FFAs. In addition, it has been shown that total body fat and circulating FFAs levels can lead to a sudden and significant increase in insulin resistance through the accumulation of high rate of TG in the heart (68). The reduced insulin's role, as a regulator of lipid homeostasis in insulin resistance, is accompanied with the increased lipogenesis in hepatocyte and lipolysis in adipocytes leading to the increased blood FFA and TG as well as the impaired handling lipids levels in adipose tissue, liver, and muscle. Thus, insulin resistance leads to some metabolic and functional disorders of the heart and the increased insulin levels stimulate the transfer of FFAs to cardiomyocytes $(69,70)$. Subsequently, hyperlipidemia and compensatory hyperinsulinemia enhance the transfer and utilization of FFAs in myocytes. Accordingly, if myocytes receive FFAs neyond their oxidative capacity, they would be accumulated leading to lipotoxicity. This phenomenon increases cardiac dysfunction through various mechanisms such as ROS production and the increased insulin signaling 
disorder (68). Accordingly, the findings of the lipid profile in the heart tissues of the studied rats showed that the tissue levels of total cholesterol and triglyceride had a significant increase in the groups $D$ and D.F compared to the group CN. Due to the wide application of iron supplements and multivitamins, and on the other hand, the extensive tissue damage in diabetes due to iron storage through high production of ROS, low iron intake in the diet is recommended to have a beneficial effect on lowering serum and tissue cholesterol and triglycerides levels as well as heart pathology.

Additionally, it was indicated that the increased liver iron levels increase cholesterol by producing glutathione, which increases the activity of HMG-CoA reductase, a rate-limiting enzyme in cholesterol biosynthesis. Therefore, the increased liver iron resulted from supplements is likely to cause lipemia, cardiac TG accumulation, and severe pathological changes $(51,71,72)$. The findings of the present study confirmed the possible effect of $\omega-3$ PUFAs supplementation on lowering triglycerides and total cholesterol levels in type 2 diabetics, which is line with the findings reported by Friday et al. (1989) and Rudkowska (2010) $(44,73)$. Considering the relationship between blood FFAs levels and cardiac TGs accumulation (74), it is expected that $\omega-3$ PUFAs are effective on reducing cardiac TGs through reducing plasma TG levels, improving lipemia by stimulating the intestine to reduce chylomicron secretion, increasing LPL activity and tissue blood flow, and improving the stimulatory effect of insulin and PPARs receptors on increasing chylomicron clearance $(75,76)$. The present study revealed the reduced tissue levels of total cholesterol and TG in the group D.w compared to the other diabetic groups; however, this reduction was only significant in comparison with the group D.F.

Histological findings revealed some pathological changes caused by diabetes in the heart of animals. Following the defects in the proteins that make up the hallmark of the heart muscle, the intercalated discs (IDs) as an intercellular communication surrounding, has emerged cardiomyopathy or other heart disorders $(77,78)$. Besides, changes in the organization of the layered structure of heart tissue along with changes in the deformation and location of the myocytes nucleus, which is usually spindle-shaped and located along with the longitudinal axis or in the center of the cell, may indicate a change in the morphology of the heart muscle cell in diabetes $(79,80)$. In conclusion, the findings of this study confirmed the devastating effects of iron on the anti-inflammatory effect of omega-3 polyunsaturated fatty acids on the heart of diabetic rats

\section{Conclusion}

In people with T2DM, the inflammatory conditions caused by hyperglycemia can be reduced by $\omega-3$ PUFAs as anti-inflammatory agents. It is likely that the increased peroxidation of $\omega-3$ PUFAs in the presence of iron as well as high glucose concentrations may reduce their antioxidant properties. Accordingly, it can be suggested that modifying the way of taking these supplements may minimize the prevalence of diabetes' complications, especially cardiovascular disease. However, more research is required to support this study.

\section{Declarations}




\section{Acknowledgment}

The authors thank the animal house of Hamadan University of Medical Sciences for supporting the research

\section{Ethical Approval and consent to Participate}

All processes for the animal study were accepted by the Research Committee of Hamadan University of Medical Sciences, Iran (Res: IR.UMSHA.REC.1398.316).

\section{Consent to Publish}

The authors listed on the title page have read the manuscript.

\section{Authors Contributions (please use initials)}

MKH-A and RA conceived and designed research. MKH-A and MB conducted experiments. NZ and AN analyzed data. MKH-A and RA wrote the manuscript. All authors read and approved the manuscript and all data were generated in-house and that no paper mill was used.

\section{Funding}

This study has been adapted from MSc. Thesis at Hamadan University of Medical Sciences. The study was funded by Vice-chancellor for Research and Technology, Hamadan University of Medical Sciences (Grant No. 9805013350).

\section{Competing Interests}

The authors declare there are no competing interests.

\section{Availability of data and materials}

All data used and analyzed during the current study are included in this manuscript and available from the corresponding author on reasonable request.

\section{References}

1. El-Moselhy MA, Taye A, Sharkawi SS, El-Sisi SF, Ahmed AF. The antihyperglycemic effect of curcumin in high fat diet fed rats. Role of TNF-a and free fatty acids. Food and Chemical Toxicology. 2011;49(5):1129-40.

2. Fowler MJ. Microvascular and macrovascular complications of diabetes. Clinical diabetes. 2008;26(2):77-82.

3. Singh VP, Bali A, Singh N, Jaggi AS. Advanced glycation end products and diabetic complications. Korean J Physiol Pharmacol. 2014;18(1):1-14. 
4. Miyata T, Sugiyama S, Saito A, Kurokawa K. Reactive carbonyl compounds related uremic toxicity ("carbonyl stress"). Kidney International. 2001;59:S25-S31.

5. Bell DS. Diabetic cardiomyopathy. Diabetes Care. 2003;26(10):2949-51.

6. Tschöpe C, Walther T, Escher F, Spillmann F, Du J, Altmann C, et al. Transgenic activation of the kallikrein-kinin system inhibits intramyocardial inflammation, endothelial dysfunction and oxidative stress in experimental diabetic cardiomyopathy. FASEB journal : official publication of the Federation of American Societies for Experimental Biology. 2005;19(14):2057-9.

7. Drucker DJ, Goldfine AB. Cardiovascular safety and diabetes drug development. The Lancet. 2011;377(9770):977-9.

8. Norton GR, Candy G, Woodiwiss AJ. Aminoguanidine prevents the decreased myocardial compliance produced by streptozotocin-induced diabetes mellitus in rats. Circulation. 1996;93(10):1905-12.

9. Evangelista I, Nuti R, Picchioni T, Dotta F, Palazzuoli A. Molecular Dysfunction and Phenotypic Derangement in Diabetic Cardiomyopathy. Int J Mol Sci. 2019;20(13):3264.

10. Naidu PB, Ponmurugan P, Begum MS, Mohan K, Meriga B, RavindarNaik R, et al. Diosgenin reorganises hyperglycaemia and distorted tissue lipid profile in high-fat diet-streptozotocin-induced diabetic rats. Journal of the Science of Food and Agriculture. 2015;95(15):3177-82.

11. Derosa G, Limas CP, Macías PC, Estrella A, Maffioli P. Dietary and nutraceutical approach to type 2 diabetes. Arch Med Sci. 2014;10(2):336-44.

12. Oh DY, Talukdar S, Bae EJ, Imamura T, Morinaga H, Fan W, et al. GPR120 is an omega-3 fatty acid receptor mediating potent anti-inflammatory and insulin-sensitizing effects. Cell. 2010;142(5):68798.

13. AlDallal SM, Jena N. Prevalence of anemia in type 2 diabetic patients. Journal of Hematology. 2018;7(2):57.

14. Angelousi A, Larger E. Anaemia, a common but often unrecognized risk in diabetic patients: a review. Diabetes \& Metabolism. 2015;41(1):18-27.

15. Bosman DR, Winkler AS, Marsden JT, Macdougall IC, Watkins PJ. Anemia with erythropoietin deficiency occurs early in diabetic nephropathy. Diabetes care. 2001;24(3):495-9.

16. Gawde SR, Patel TC, Rege NN, Gajbhiye S, Uchil D. Evaluation of effects of Maṇdurabhasma on structural and functional integrity of small intestine in comparison with ferrous sulfate using an experimental model of iron deficiency anemia. Ancient science of life. 2015;34(3):134.

17. Van Campenhout A, Van Campenhout C, Lagrou AR, Abrams P, Moorkens G, Van Gaal L, et al. Impact of diabetes mellitus on the relationships between iron-, inflammatory-and oxidative stress status. Diabetes/metabolism research and reviews. 2006;22(6):444-54.

18. Silva M, de Freitas Bonomo L, de Paula Oliveira R, de Lima WG, Silva ME, Pedrosa ML. Effects of the interaction of diabetes and iron supplementation on hepatic and pancreatic tissues, oxidative stress markers, and liver peroxisome proliferator-activated receptor-a expression. Journal of clinical biochemistry and nutrition. 2011;49(2):102-8. 
19. Furman BL. Streptozotocin-induced diabetic models in mice and rats. Current protocols in pharmacology. 2015;70(1):5.47. 1-5.. 20.

20. Pari L, Karthikeyan A, Karthika P, Rathinam A. Protective effects of hesperidin on oxidative stress, dyslipidaemia and histological changes in iron-induced hepatic and renal toxicity in rats. Toxicology reports. 2015;2:46-55.

21. Avramovic N, Dragutinovic V, Krstic D, Colovic M, Trbovic A, de Luka S, et al. The effects of omega 3 fatty acid supplementation on brain tissue oxidative status in aged wistar rats. Hippokratia. 2012;16(3):241-5.

22. Wang C-Y, Liao JK. A mouse model of diet-induced obesity and insulin resistance. mTOR: Springer; 2012. p. 421-33.

23. Fleming TH, Theilen T-M, Masania J, Wunderle M, Karimi J, Vittas S, et al. Aging-dependent reduction in glyoxalase 1 delays wound healing. Gerontology. 2013;59(5):427-37.

24. Erel O. A new automated colorimetric method for measuring total oxidant status. Clinical biochemistry. 2005;38(12):1103-11.

25. Benzie IF, Strain J. [2] Ferric reducing/antioxidant power assay: direct measure of total antioxidant activity of biological fluids and modified version for simultaneous measurement of total antioxidant power and ascorbic acid concentration. Methods in enzymology. 299: Elsevier; 1999. p. 15-27.

26. Ohkawa H, Ohishi N, Yagi K. Assay for lipid peroxides in animal tissues by thiobarbituric acid reaction. Analytical Biochemistry. 1979;95(2):351-8.

27. Olson BJ, Markwell J. Assays for determination of protein concentration. Current protocols in protein science. 2007; Chapter 3:Unit 3.4.

28. Folch J, Lees M, Sloane Stanley GH. A simple method for the isolation and purification of total lipides from animal tissues. The Journal of biological chemistry. 1957;226(1):497-509.

29. Gajda AM, Pellizzon MA, Ricci MR, Ulman EA. Diet-induced metabolic syndrome in rodent models. Animal Lab News. 2007;74:775-93.

30. Gheibi S, Kashfi K, Ghasemi A. A practical guide for induction of type-2 diabetes in rat: Incorporating a high-fat diet and streptozotocin. Biomedicine \& pharmacotherapy = Biomedecine \& pharmacotherapie. 2017;95:605-13.

31. Ghibaudi L, Cook J, Farley C, Van Heek M, Hwa JJ. Fat intake affects adiposity, comorbidity factors, and energy metabolism of sprague-dawley rats. Obesity research. 2002;10(9):956-63.

32. Storlien LH, James DE, Burleigh KM, Chisholm DJ, Kraegen EW. Fat feeding causes widespread in vivo insulin resistance, decreased energy expenditure, and obesity in rats. American Journal of Physiology-Endocrinology and Metabolism. 1986;251(5):E576-E83.

33. Srinivasan K, Patole PS, Kaul CL, Ramarao P. Reversal of glucose intolerance by by pioglitazone in high fat diet-fed rats. Methods and findings in experimental and clinical pharmacology. 2004;26(5):327-33. 
34. Srinivasan K, Viswanad B, Asrat L, Kaul C, Ramarao P. Combination of high-fat diet-fed and low-dose streptozotocin-treated rat: a model for type 2 diabetes and pharmacological screening. Pharmacological research. 2005;52(4):313-20.

35. Wang HJ, Shen W, Neng J, Wu T, Li YJ. Low dose streptozotocin (STZ) combined with high energy intake can effectively induce type 2 diabetes through altering the related gene expression. Asia Pacific journal of clinical nutrition. 2007;16:412.

36. Gundala NK, Das UN. Arachidonic acid-rich ARASCO oil has anti-inflammatory and antidiabetic actions against streptozotocin+ high fat diet induced diabetes mellitus in Wistar rats. Nutrition. 2019;66:203-18.

37. Jump DB. Dietary polyunsaturated fatty acids and regulation of gene transcription. Current opinion in lipidology. 2002;13(2):155-64.

38. Ukropec J, Reseland J, Gasperikova D, Demcakova E, Madsen L, Berge R, et al. The hypotriglyceridemic effect of dietary $n-3$ FA is associated with increased $\beta$-oxidation and reduced leptin expression. Lipids. 2003;38(10):1023-9.

39. Li X, Li H, Lu N, Feng Y, Huang Y, Gao Z. Iron increases liver injury through oxidative/nitrative stress in diabetic rats: Involvement of nitrotyrosination of glucokinase. Biochimie. 2012;94(12):2620-7.

40. Sahin K, Onderci M, Tuzcu M, Ustundag B, Cikim G, Ozercan IH, et al. Effect of chromium on carbohydrate and lipid metabolism in a rat model of type 2 diabetes mellitus: the fat-fed, streptozotocin-treated rat. Metabolism: clinical and experimental. 2007;56(9):1233-40.

41. Luo J, Quan J, Tsai J, Hobensack CK, Sullivan C, Hector R, et al. Nongenetic mouse models of noninsulin-dependent diabetes mellitus. Metabolism: clinical and experimental. 1998;47(6):663-8.

42. Poudyal H, Panchal SK, Diwan V, Brown L. Omega-3 fatty acids and metabolic syndrome: effects and emerging mechanisms of action. Progress in lipid research. 2011;50(4):372-87.

43. Borkman M, Chisholm DJ, Furler SM, Storlien LH, Kraegen EW, Simons LA, et al. Effects of Fish Oil Supplementation on Glucose and Lipid Metabolism in NIDDM. Diabetes. 1989;38(10):1314-9.

44. Friday KE, Childs MT, Tsunehara CH, Fujimoto WY, Bierman EL, Ensinck JW. Elevated Plasma Glucose and Lowered Triglyceride Levels From Omega-3 Fatty Acid Supplementation in Type II Diabetes. Diabetes Care. 1989;12(4):276-81.

45. Luo J, Rizkalla SW, Vidal H, Oppert JM, Colas C, Boussairi A, et al. Moderate intake of n-3 fatty acids for 2 months has no detrimental effect on glucose metabolism and could ameliorate the lipid profile in type 2 diabetic men. Results of a controlled study. Diabetes Care. 1998;21(5):717-24.

46. Rivellese AA, Maffettone A, lovine C, Di Marino L, Annuzzi G, Mancini M, et al. Long-Term Effects of Fish Oil on Insulin Resistance and Plasma Lipoproteins in NIDDM Patients With Hypertriglyceridemia. Diabetes Care. 1996;19(11):1207-13.

47. Arulselvan P, Subramanian SP. Beneficial effects of Murraya koenigii leaves on antioxidant defense system and ultra structural changes of pancreatic $\beta$-cells in experimental diabetes in rats. ChemicoBiological Interactions. 2007;165(2):155-64. 
48. Zhang XF, Tan BKH. Antihyperglycaemic and anti-oxidant properties of andrographis paniculata in normal and diabetic rats. Clinical and Experimental Pharmacology and Physiology. 2000;27(56):358-63.

49. Aksakal E, Akaras N, Kurt M, Tanboga IH, Halici Z, Odabasoglu F, et al. The role of oxidative stress in diabetic cardiomyopathy: an experimental study. European review for medical and pharmacological sciences. 2011;15(11):1241-6.

50. Booth AJ, Hadley R, Cornett AM, Dreffs AA, Matthes SA, Tsui JL, et al. Acellular normal and fibrotic human lung matrices as a culture system for in vitro investigation. American journal of respiratory and critical care medicine. 2012;186(9):866-76.

51. Sampaio AFS, Silva M, Dornas WC, Costa DC, Silva ME, dos Santos RC, et al. Iron toxicity mediated by oxidative stress enhances tissue damage in an animal model of diabetes. Biometals. 2014;27(2):349-61.

52. Ginty AT, Conklin SM. Preliminary evidence that acute long-chain omega-3 supplementation reduces cardiovascular reactivity to mental stress: a randomized and placebo controlled trial. Biological psychology. 2012;89(1):269-72.

53. Glahn RP, Wien EM, Van Campen DR, Miller DD. Caco-2 cell iron uptake from meat and casein digests parallels in vivo studies: use of a novel in vitro method for rapid estimation of iron bioavailability. The Journal of nutrition. 1996;126(1):332-9.

54. Knight J, McClellan L. Metal-catalyzed peroxidation of polyunsaturated fatty acids. Annals of Clinical \& Laboratory Science. 1989;19(5):377-82.

55. Bao W, Rong Y, Rong S, Liu L. Dietary iron intake, body iron stores, and the risk of type 2 diabetes: a systematic review and meta-analysis. BMC medicine. 2012;10:119.

56. Hong Sheng C, So Ha T, Khalid Abdul K. Therapeutic Agents Targeting at AGE-RAGE Axis for the Treatment of Diabetes and Cardiovascular Disease: A Review of Clinical Evidence. Clinical Diabetes and Research. 2017;1(1).

57. Schratt GM, Tuebing F, Nigh EA, Kane CG, Sabatini ME, Kiebler M, et al. A brain-specific microRNA regulates dendritic spine development. Nature. 2006;439(7074):283-9.

58. Swaminathan S, Fonseca VA, Alam MG, Shah SV. The role of iron in diabetes and its complications. Diabetes care. 2007;30(7):1926-33.

59. Chen J, Shearer GC, Chen Q, Healy CL, Beyer AJ, Nareddy VB, et al. Omega-3 fatty acids prevent pressure overload-induced cardiac fibrosis through activation of cyclic GMP/protein kinase $\mathrm{G}$ signaling in cardiac fibroblasts. Circulation. 2011;123(6):584-93.

60. Cintra DE, Ropelle ER, Moraes JC, Pauli JR, Morari J, de Souza CT, et al. Unsaturated Fatty Acids Revert Diet-Induced Hypothalamic Inflammation in Obesity. PLOS ONE. 2012;7(1):e30571.

61. Felau SM, Sales LP, Solis MY, Hayashi AP, Roschel H, Sá-Pinto AL, et al. Omega-3 Fatty Acid Supplementation Improves Endothelial Function in Primary Antiphospholipid Syndrome: A SmallScale Randomized Double-Blind Placebo-Controlled Trial. Frontiers in immunology. 2018;9:336. 
62. Fu M-X, Requena JR, Jenkins AJ, Lyons TJ, Baynes JW, Thorpe SR. The advanced glycation end product, $\mathrm{N}$-(carboxymethyl) lysine, is a product of both lipid peroxidation and glycoxidation reactions. Journal of Biological Chemistry. 1996;271(17):9982-6.

63. Baum P, Kosacka J, Estrela-Lopis I, Woidt K, Serke H, Paeschke S, et al. The role of nerve inflammation and exogenous iron load in experimental peripheral diabetic neuropathy (PDN). Metabolism: clinical and experimental. 2016;65(4):391-405.

64. Srinivasan K, Viswanad B, Asrat L, Kaul CL, Ramarao P. Combination of high-fat diet-fed and lowdose streptozotocin-treated rat: A model for type 2 diabetes and pharmacological screening. Pharmacological Research. 2005;52(4):313-20.

65. Rijzewijk LJ, van der Meer RW, Smit JW, Diamant M, Bax JJ, Hammer S, et al. Myocardial steatosis is an independent predictor of diastolic dysfunction in type 2 diabetes mellitus. Journal of the American College of Cardiology. 2008;52(22):1793-9.

66. Korosoglou G, Humpert PM, Ahrens J, Oikonomou D, Osman NF, Gitsioudis G, et al. Left ventricular diastolic function in type 2 diabetes mellitus is associated with myocardial triglyceride content but not with impaired myocardial perfusion reserve. Journal of magnetic resonance imaging : JMRI. 2012;35(4):804-11.

67. McGavock J, Szczepaniak LS, Ayers CR, Abdullah SM, See R, Gore MO, et al. The effects of rosiglitazone on myocardial triglyceride content in patients with type 2 diabetes: a randomised, placebo-controlled trial. Diabetes \& vascular disease research. 2012;9(2):131-7.

68. Turer AT, Hill JA, Elmquist JK, Scherer PE. Adipose tissue biology and cardiomyopathy: translational implications. Circulation research. 2012;111(12):1565-77.

69. Guilherme A, Virbasius JV, Puri V, Czech MP. Adipocyte dysfunctions linking obesity to insulin resistance and type 2 diabetes. Nature reviews Molecular cell biology. 2008;9(5):367-77.

70. Luiken JJ, Koonen DP, Willems J, Zorzano A, Becker C, Fischer Y, et al. Insulin stimulates long-chain fatty acid utilization by rat cardiac myocytes through cellular redistribution of FAT/CD36. Diabetes. 2002;51(10):3113-9.

71. Bureau I, Lewis CG, Fields M. Effect of Hepatic Iron on Hypercholesterolemia and Hypertriacylglycerolemia in Copper-Deficient Fructose-Fed Rats. Nutrition. 1998;14(4):366-71.

72. McGavock JM, Lingvay I, Zib I, Tillery T, Salas N, Unger R, et al. Cardiac steatosis in diabetes mellitus: a 1H-magnetic resonance spectroscopy study. Circulation. 2007;116(10):1170-5.

73. Rudkowska I. Fish oils for cardiovascular disease: impact on diabetes. Maturitas. 2010;67(1):25-8.

74. Iozzo P, Lautamaki R, Borra R, Lehto H-R, Bucci M, Viljanen A, et al. Contribution of Glucose Tolerance and Gender to Cardiac Adiposity. The Journal of Clinical Endocrinology \& Metabolism. 2009;94(11):4472-82.

75. Harris WS, Hustvedt BE, Hagen E, Green MH, Lu G, Drevon CA. N-3 fatty acids and chylomicron metabolism in the rat. Journal of lipid research. 1997;38(3):503-15.

76. Park Y, Harris WS. Omega-3 fatty acid supplementation accelerates chylomicron triglyceride clearance. Journal of lipid research. 2003;44(3):455-63. 
77. Bennett PM, Maggs AM, Baines AJ, Pinder JC. The transitional junction: a new functional subcellular domain at the intercalated disc. Molecular biology of the cell. 2006;17(4):2091-100.

78. Mandache E, Popescu LM, Gherghiceanu M. Myocardial interstitial Cajal-like cells (ICLC) and their nanostructural relationships with intercalated discs: shed vesicles as intermediates. J Cell Mol Med. 2007;11(5):1175-84.

79. Canale ED, Campbell GR, Smolich JJ, Campbell JH. Morphology of Cardiac Muscle. Cardiac Muscle. Berlin, Heidelberg: Springer Berlin Heidelberg; 1986. p. 8-51.

80. Rolo AP, Palmeira CM. Diabetes and mitochondrial function: role of hyperglycemia and oxidative stress. Toxicology and applied pharmacology. 2006;212(2):167-78.

\section{Figures}
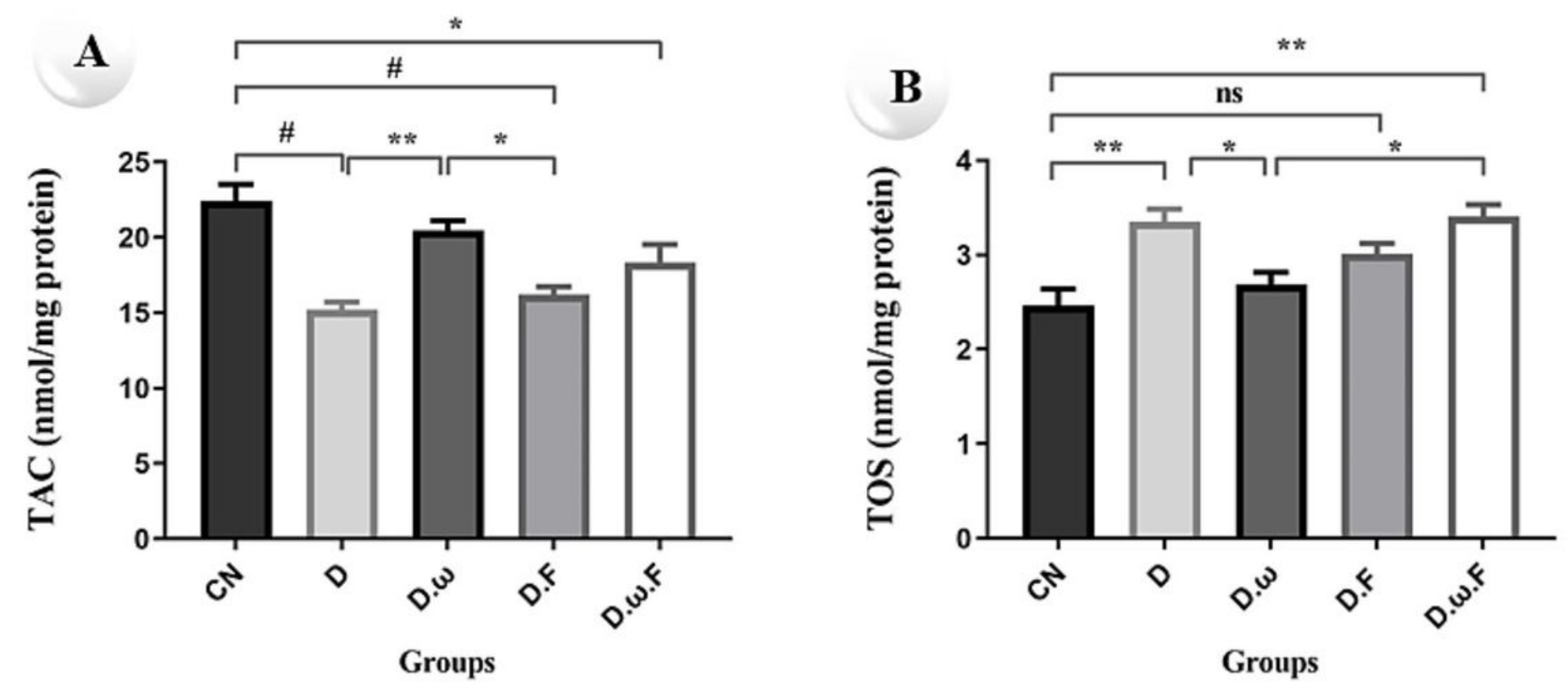

Groups
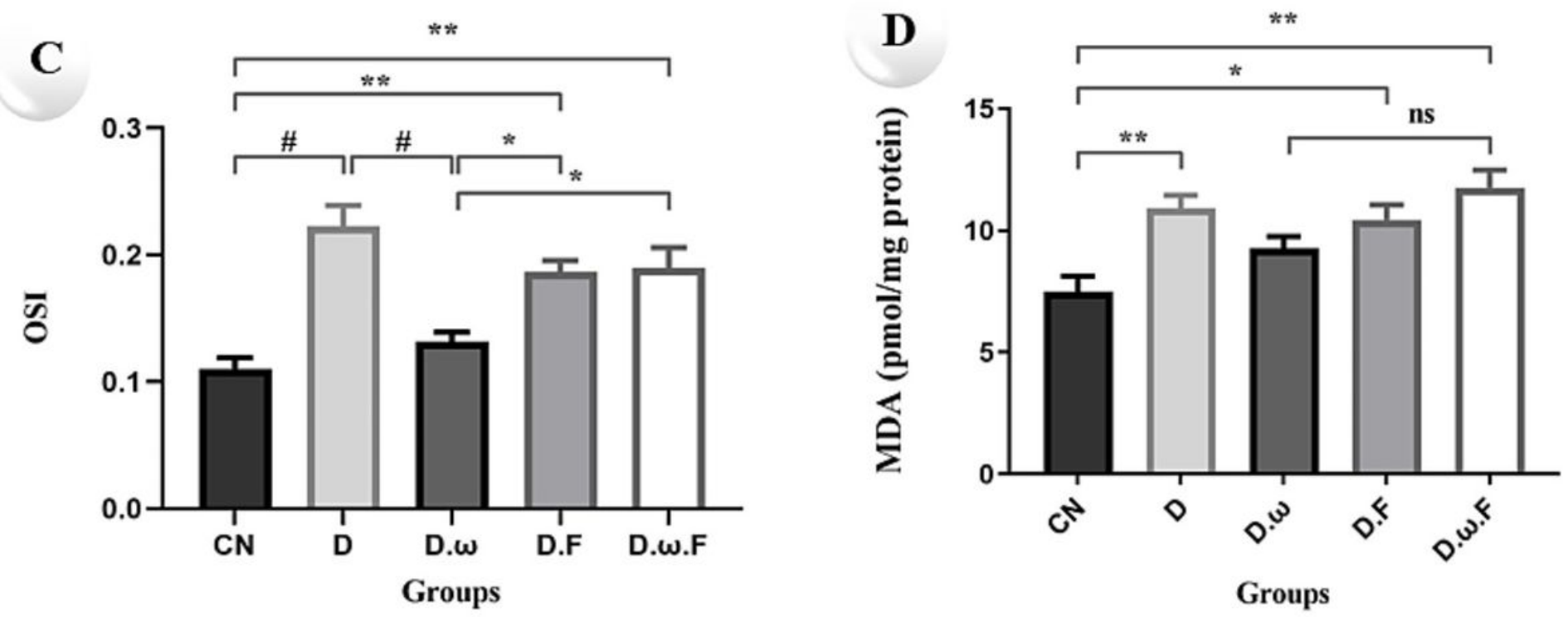
Figure 1

The effect of treatments on the oxidative stress markers in cardiac tissue of studied animals $(n=6) . A)$ Total antioxidant capacity (TAC), B) Total oxidant status (TOS), C) Oxidative stress index (OSI), D) Malondialdehyde (MDA), CN: Control normal group, D: Diabetic control group, D.w: The diabetic group received $\omega$-3 PUFAs supplement, D.F: The diabetic group received Fe2+ supplement, D.w.F: The diabetic group received $\omega-3$ PUFAs and Fe2+ supplements: Data are shown as mean $\pm S E M$. $\left({ }^{\star} P<0.05, * \star p<0.01\right.$, $\# p<0.001$, ns $p>0.05)$.

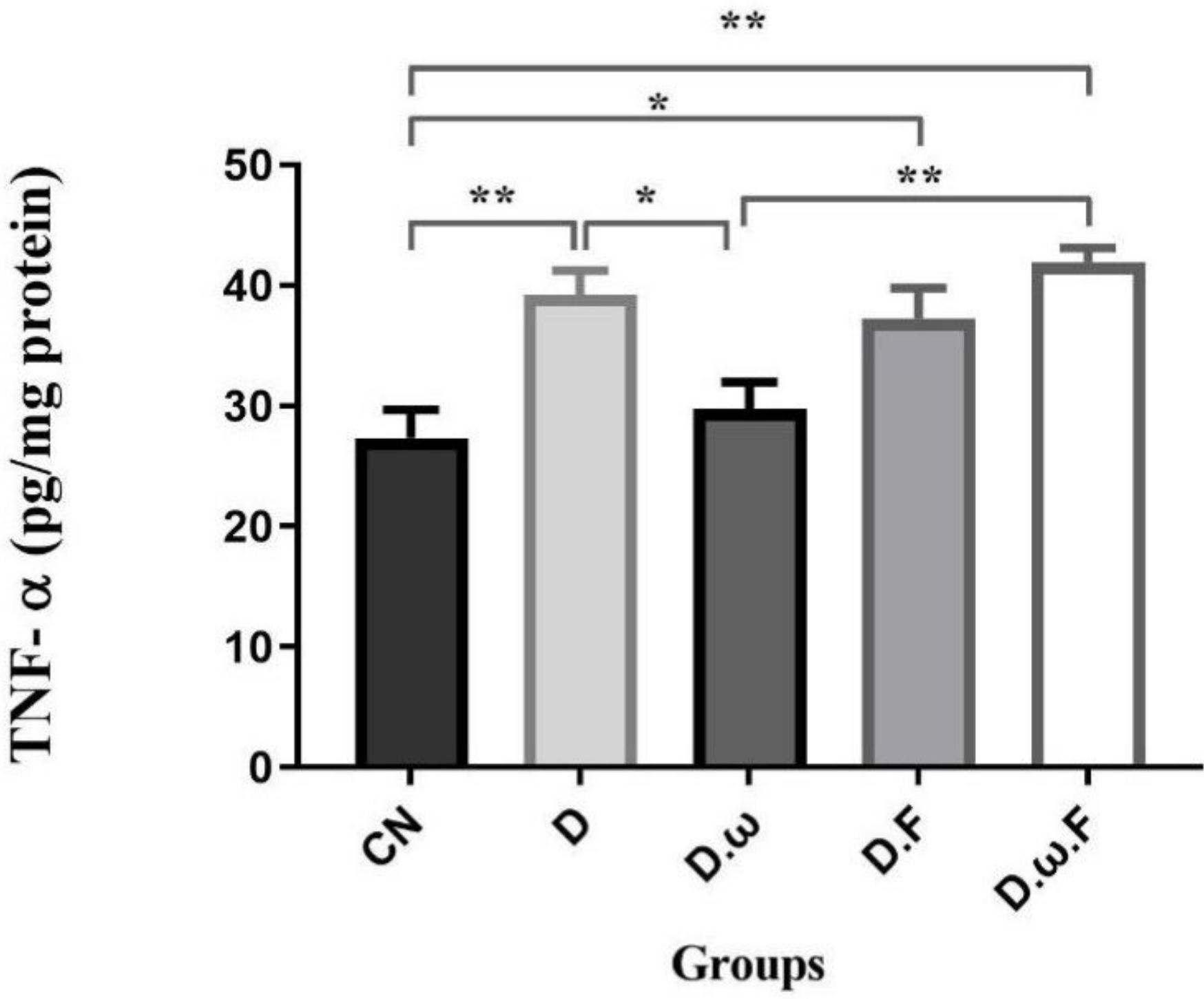

Figure 2

The effect of treatments on TNF-a protein in cardiac tissue of studied rats $(n=6)$. TNF-a: Tumor necrosis factor- $a, C N$ : Control normal group, D: Diabetic control group, D. $\omega$ : the diabetic group received $\omega-3$ PUFAs supplement, D.F: the diabetic group received Fe2+ supplement, D. $\omega . F$ : the diabetic group received $\omega-3$ PUFAs and Fe2 + supplements. Data are shown as mean \pm SEM. $\left({ }^{\star} p<0.05, * \star p<0.01\right)$. 

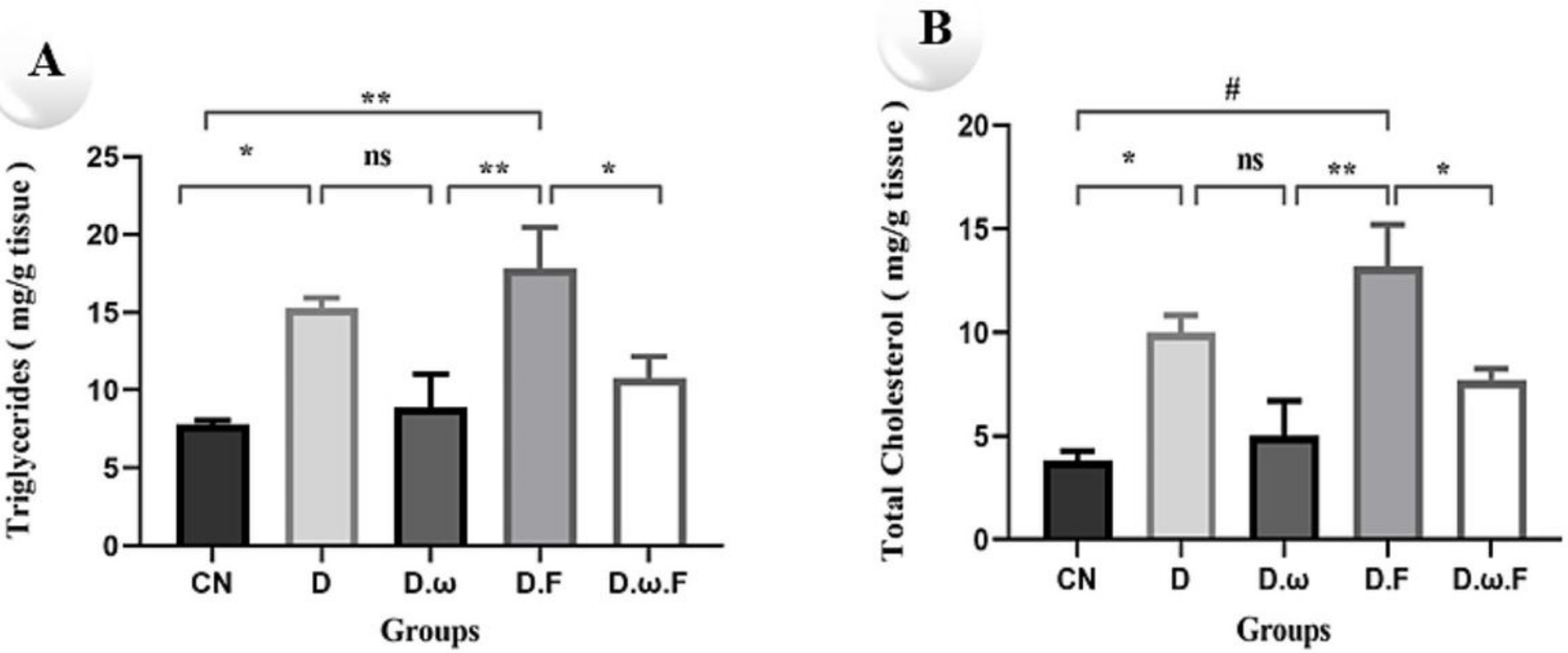

Figure 3

The effect of treatments on triglyceride and total cholesterol levels in cardiac tissue of studied rats $(n=6)$. A) Triglyceride levels in tissue, B) Total cholesterol levels in tissue. CN: Control normal group, D: Diabetic control group, D. $\omega$ : the diabetic group received $\omega-3$ PUFAs supplement, D.F: the diabetic group received Fe2+ supplement, D. $\omega . F$ : the diabetic group received $\omega-3$ PUFAs and Fe2+ supplements. Data are shown as mean \pm SEM. ( ${ }^{*} p<0.05, * * p<0.01, \# p<0.001$, ns $\left.p>0.05\right)$. 

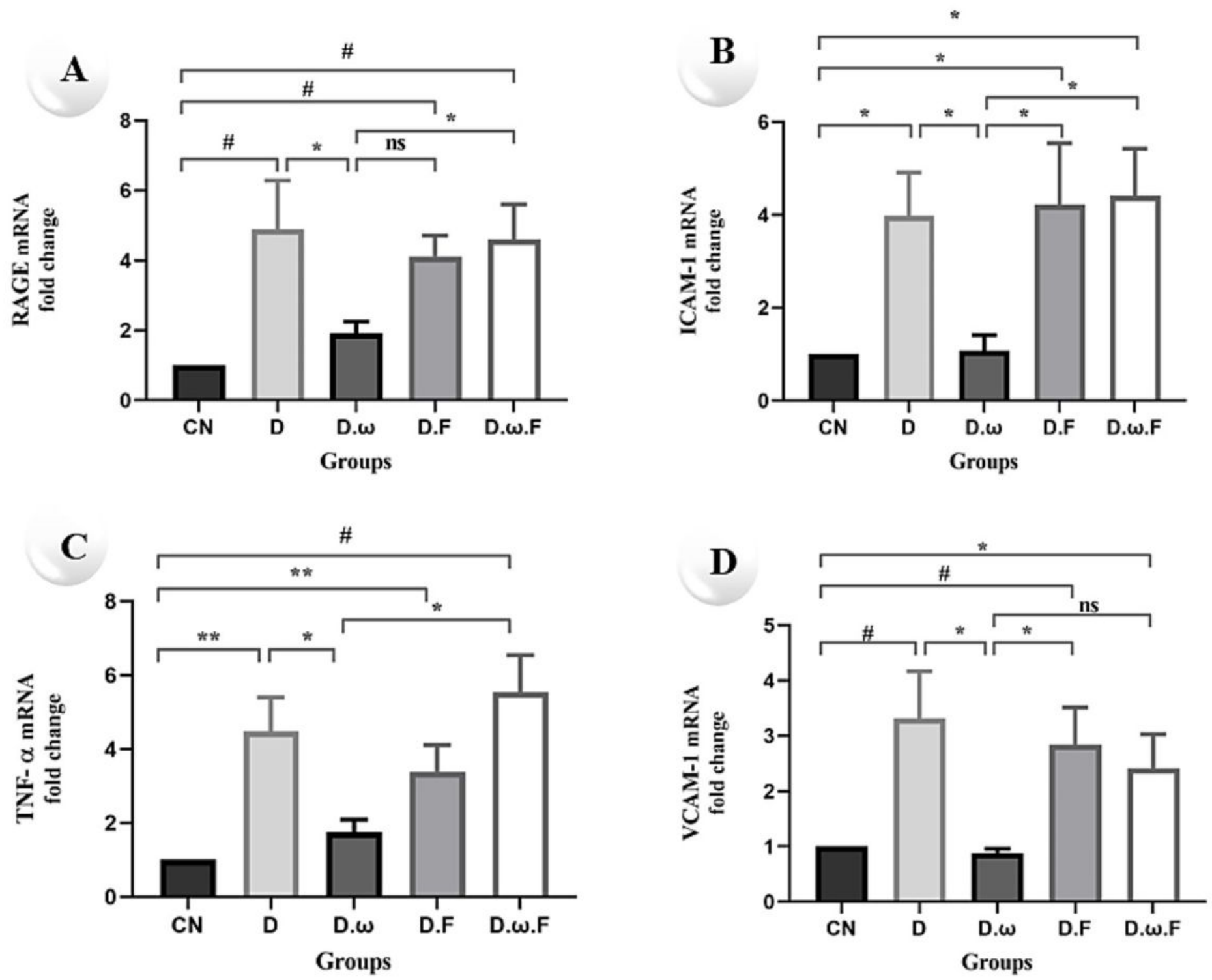

Figure 4

The effect of treatments on mRNA expression of RAGE, TNF-a, ICAM-1 and VCAM- 1 genes in cardiac tissue of studied rats ( $n=6)$. A) RAGE gene expression level, B) ICAM-1 gene expression level, C) TNF-a gene expression level and D) VCAM-1 gene expression level. RAGE: Receptor for advanced glycation end products, TNF-a: tumor necrosis factor-a, ICAM-1: Intercellular Adhesion Molecule-1, VCAM-1: Vascular Cell Adhesion Molecule-1. CN: Control normal group, D: Diabetic control group, D.w: the diabetic group received $\omega$-3 PUFAs supplement, D.F: the diabetic group received Fe2+ supplement, D.w.F: the diabetic group received $\omega-3$ PUFAs and Fe2+ supplements. Data are shown as mean \pm SEM. $\left({ }^{*} p<0.05, * \star p<0.01\right.$, $\# p<0.001$, ns $p>0.05)$. 

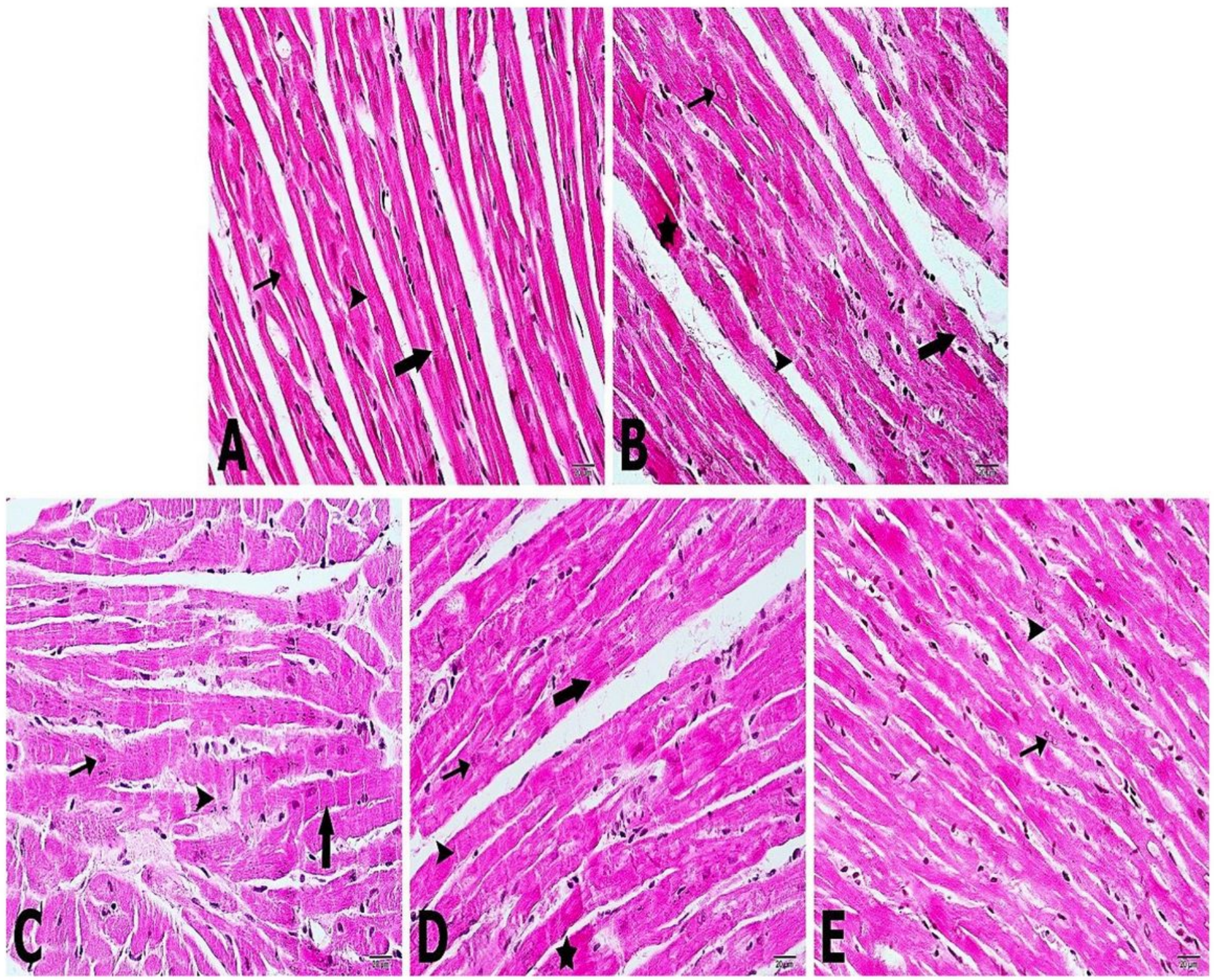

\section{Figure 5}

Histopathology of heart tissue with H\&E staining and magnification of $400 \mathrm{X}$ : $\mathrm{CN}$ group (A): cross striation $(\uparrow)$, typical nuclei $(\uparrow)$ which are interconnected longitudinally by intercalated discs (IDs) ( $\mathbf{\Delta}), D$ group (B): fragmented cardiomyofibers $(\uparrow)$, square-shaped swelling nuclei $(\uparrow)$, hypercontracted segments (*) along with widened ID ( $\boldsymbol{\Delta})$, D.F group (C): degenerative changes $(\uparrow)$, nuclear fading $(\uparrow)$, and widening of the IDs $(\boldsymbol{\Delta})$, D.w.F group (D): fragmented cardiomyocytes $\left({ }^{*}\right)$, ruptured myofibrils $(\uparrow)$, degenerating nuclei $(\uparrow)$, widening the gap of IDs $(\mathbf{\Lambda})$, D.w group (E): regeneration of the myocardial tissue toward the normal histology with rare if any detectable degenerative changes such as squareshaped nuclei $(\uparrow)$ and gapping the intercalated discs $(\boldsymbol{\Lambda})$.

\section{Supplementary Files}

This is a list of supplementary files associated with this preprint. Click to download. 
- GENSCopy.pzfx

- proTNF.TAC.Lip.MDA.TOSCopy.pzfx 